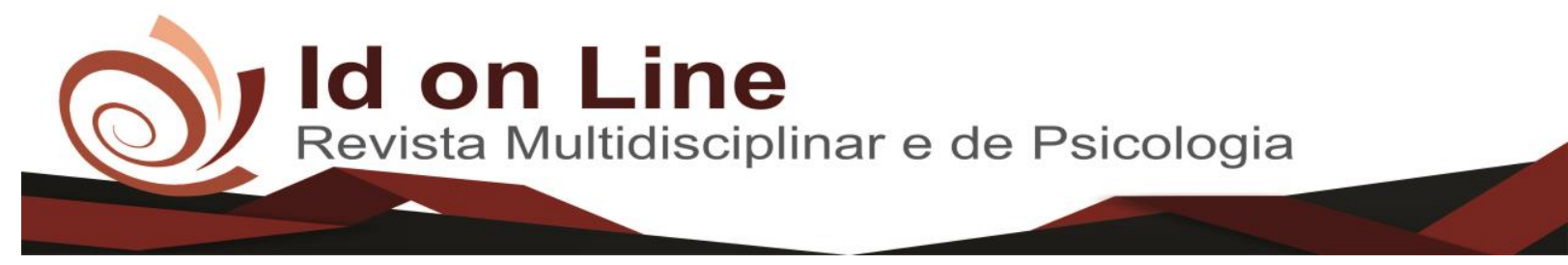

Artigo

\title{
Políticas e Programas Públicos que Oportunizam a Inserção do Jovem no Mercado de Trabalho
}

\author{
Andreza Bispo da Silva ${ }^{1}$; Antonia Valdelucia Costa ${ }^{2}$
}

\begin{abstract}
Resumo: O presente trabalho expõe a relação do jovem com o mercado de trabalho e quais políticas/programas públicos existem para auxiliar o mesmo, analisando as dificuldades enfrentadas para seu ingresso no mundo do trabalho, já que se trata de um mercado que cada vez mais exige pessoas qualificadas e que possuam experiência profissional, pesquisando quais políticas/programas púbicos foram criados para estimular a inserção dos jovens no mercado de trabalho, as regras de participação em tais programas. Em especial o Programa Jovem Aprendiz que estar estabelecido na Lei 10.097 de 2000, pode-se dizer que se trata da junção dos outros programas criados anteriormente. Com base nessa lei é feito o contrato de aprendizagem onde estão estabelecidos todos os direitos do Jovem Aprendiz. A pesquisa de cunho bibliográfico foi feita com base em artigos, livros, lei e sites confiáveis, sem alterar o ambiente natural das informações, apresentando as políticas/programas que possibilitam ao jovem capacitação, experiência profissional e melhores oportunidades no mercado de trabalho.
\end{abstract}

Palavras Chave: Jovem. Mercado de Trabalho. Políticas/Programas Público

\section{Public Policies and Programs that Opportunize the Young People Insertion in the Labor Market}

\begin{abstract}
The present work exposes young's relationship with the labor market and what policies/public programs exist to assist it, analyzing the difficulties faced to your entry into the world of work, since this is a market that increasingly requires qualified people and they have professional experience, researching what policies/public programs have been created to stimulate the integration of young people into the labor market, the rules for participation in such programs. In particular the young Apprentice Program to be established in Law 10,097 of 2000 , it can be said that this is the junction of other programs created previously. Based on this law is done the learning contract where are established all rights of the young apprentice. The research of mark was based on bibliographic articles, books, law and trusted sites, without changing the natural environment of information, showing the policies/programs that provide young training, professional experience and best opportunities in the labor market.
\end{abstract}

Keywords: Youth. Labor Market. Policies / Programs Public

\section{Introdução}

Diante de um país que enfrenta dificuldades políticas e econômicas como o Brasil, as oportunidades de trabalho se tornam cada vez menores. Para os jovens, esse cenário ainda é

\footnotetext{
1 Concludente do Curso de Ciências Contábeis do Centro Universitário Dr. Leão Sampaio. - UNILEÃO. E-mail: andrezahbs@outlook.com

${ }^{2}$ Orientadora. Ms. em Ciência da Educação pela UTIC-PY. .Docente da UNILEÃO. E-mail: valdelucia@leaoampaio.edu.br; valdeluciacosta@hotmal.com 
mais complexo, pois como a maioria não possui experiência profissional formalizada, a inserção no mercado de trabalho se torna mais difícil. Obter uma boa qualificação técnica, acadêmica e comportamental é necessária para conseguir uma colocação no mercado de trabalho.

A formação dos adolescentes, que na maioria das vezes faz parte da classe baixa do país e que precisam do trabalho para sustentar a família e a si mesmo, se trata de um investimento no futuro visto que são os mesmos que farão parte de uma sociedade economicamente ativa e que trarão riquezas para o Brasil. Contudo, entender o que regulamente as políticas/programas públicos que auxiliam e capacitam os jovens para o mercado de trabalho é de suma importância para as empresas e a sociedade em geral.

Conhecer tais programas/políticas e saber os critérios de participação é fundamental para os jovens que buscam a oportunidade do primeiro emprego e para as organizações que buscam seguir as leis e contribuir com a sociedade.

Partindo desse pressuposto, indaga-se: Como as políticas/programas públicos intervêm na qualificação e inserção dos jovens no mercado de trabalho? Ao decorrer deste trabalho serão esclarecidos quais programas existem e como funcionam.

Portanto, o presente trabalho teve como objetivo apresentar as políticas/programas existentes que capacitam e estimulam a inserção dos jovens no mundo do trabalho, com um foco maior para Lei da Aprendizagem, Lei $\mathrm{n}^{\circ}$ 10.097/2000, descrevendo cada um dos programas para que cada jovem saiba qual o mais adaptável a si de acordo com sua realidade. Certamente o trabalho contribuirá para um melhor entendimento sobre a inserção do jovem no mundo do trabalho.

Esse artigo foi desenvolvido através de uma pesquisa bibliográfica de cunho descritivo e com procedimentos qualitativos, onde o pesquisador não interfere no resultado pesquisado, analisando assim os fatos em seus ambientes naturais.

Pode-se observar que as políticas/programas públicos se fez necessário para inserção dos jovens no mercado de trabalho com a devida qualificação que as empresas exigem. Além disso, agem efetivamente na diminuição da quantidade de jovens que se submetem a situações precárias para trabalhar. 


\section{Origem e Significado do Trabalho}

Desde os primórdios que o trabalho existe. De acordo com a Bíblia sagrada, em Gênesis, capítulo 3, versículo19, que o trabalho é citado, mas como uma forma de punição para a expiação dos pecados, onde se afirma: "comerás o pão com o suor da tua fronte".

A palavra trabalho tem sua origem etimologicamente no francês travailler e também no espanhol trabajar Ambas expressões possuem uma só origem: o latim vulgar tripiliare /tripalium, que era um instrumento de tortura usado para castigar os escravos (MARTINS, 2000). Essa ferramenta possuía três pontas/hastes.

A palavra latina laborare significava o balanço do corpo do escravo ao carregar fardos pesados indicando o sofrimento e mau trato sofrido pelo ser escravo (ALBOTNOZ, 2002).

Ao se falar em trabalho, necessário se faz a sua conceituação ao longo da história, pois o mesmo existe desde que o mundo é mundo; o homem sempre necessitou do trabalho para assim poder suprir suas necessidades básicas de sobrevivência. Desde os primórdios que o homem trabalhava para poder consumir, sobreviver.

De acordo com as palavras de Carmo (1977, p. 15), trabalho pode ser conceituado como "toda atividade realizada pelo homem civilizado que transforma a natureza pela inteligência".

Há que se admitir que o trabalho é um fator essencial na vida do ser humano, pois é através dele que o homem garante a sua sobrevivência.

A jornada de trabalho, que atualmente é de 44/48 horas, já foi de até 18 horas, no século XIV. Mais adiante, no século XVIII, as jornadas de trabalho continuaram ainda muito excessivas, pois perduravam entre 12 a 16 horas diárias, especialmente para as mulheres e os menores de idade (MARTINS, 2000).

O trabalho é fundamental para os indivíduos, é pois, segundo Araújo e Sachuk, (2007), uma forma de proporcionar uma maior dignidade social, uma identidade funcional.

O trabalho dignifica o homem, pois lhe fornece uma condição de sobrevivência, além de respeitar a sua dignidade e respaldo social, uma vez que o insere satisfatoriamente na sociedade como ser produtivo e contributivo.

\section{Conceituando o Mercado de Trabalho}

Muitas são os conceitos para o Mercado de trabalho, mas é possível afirmar que o mesmo refere-se às diversas formas de trabalho que existem e estão à disposição da sociedade, devidamente remunerados. 
Silva, Oliveira e Oliveira (2015), afirmam que o mercado de trabalho é o espaço e que há a demanda e oportunidades de trabalho ofertado pelas organizações objetivando adquirir profissionais qualificados para ocuparem determinadas funções e/ou cargos.

Na visão de Chiavenato (2009 p.1), "mercado de trabalho é uma troca de produtos e bens, visando atender ambos os lados, de maneira que todos saiam satisfeitos". Logo, pode-se afirmar que o mercado de trabalho leva à satisfação das pessoas envolvidas que buscam o atingir seus objetivos com êxito.

Para Castilho (2018, p. 01), "O intercâmbio cotidiano de capacidade produtiva entre trabalhadores e empresas" é o que caracteriza o mercado de trabalho.

O mercado de trabalho passou por muitas transformações e reestruturações desde a década de 1990, pois com o advento das tecnologias ocorreram mudanças nas formas de organizar o trabalho, e que continuam cada vez mais a passar por mudanças, acompanhado o ritmo de inovações (SCALON, 2009).

Chiavenato (2014, p. 84) afirma que "o mundo em acelerada mudança, o impacto do desenvolvimento tecnológico, as novas formas de organização e configuração empresarial, novos produtos e serviços e novos processos de trabalho". Assim, é viável afirmar que o homem necessita estar sempre em busca de novos conhecimentos para estar e ser inserido no mercado de trabalho que está em constante evolução.

Nesse sentido, Borges (2010) afirma o mercado de trabalho exige a qualificação pessoal e profissional do trabalhador, pois sem esta, não será inserido neste mundo tão competitivo.

O mercado de trabalho se divide em setor primário, setor secundário e setor terciário. Estes se complementam, pois o setor primário está ligado relacionado à matéria prima, agricultura, etc, enquanto que o secundário se reporta à questão das relações de trabalho que e utilizam do primário para a modificação de seus produtos. Já o setor terciário, está relacionado às relações interpessoais (SILVA, 2014).

Dentro dessas conceituações acerca do mercado de trabalho, necessário se conhecer sua classificação, pois há o trabalho formal e o informal, que fazem a economia do país se desenvolver. 


\section{Classificação do Trabalho}

\section{Trabalho Formal}

Silva (2014), afirma que o trabalho formal é aquele em que há o registro legal, ou seja, que segue as normas trabalhistas com a Carteira de trabalho devidamente assinada, gerando assim o contrato formal. Para o mesmo autor, o trabalho informal é exatamente o contrário do formal, pois não há registro legalizando a relação trabalhista.

O Guia Trabalhista (2018, p. 1), define trabalho formal como aquele em que os empregados[...] "recebem salário mensal e comprovado por meio de holerites ou contracheques, estão amparados por lei e tem direito a aposentadoria de acordo com as condições previstas na legislação vigente."

O trabalho formal é uma forma de "garantia" do trabalhador, pois este é o que o empregado tem sua CTPS - Carteira de Trabalho e Previdência Social, tendo todos os benefícios trabalhistas garantidos pela CLT - Consolidação das Leis do Trabalho.

\section{Trabalho informal}

Com relação ao trabalho informal, o Guia Trabalhista preceitua que é

\footnotetext{
Aquele que ocorre quando o empregado não possui registro na carteira de trabalho e, consequentemente, também não recebe os benefícios determinados pela CLT (Consolidação das Leis de Trabalho), como licenças, férias, aposentadoria, segurodesemprego, FGTS e outros (GUIA TRABALHSITA, 2018, p. 1).
}

Este tipo de trabalho não possui registro formal, e consequentemente, não há nenhum tipo de benefícios garantido pela CLT. Consiste, portanto, no trabalho autônomo.

Nos dias atuais, essa forma de trabalho tem crescido muito, ocasionado pelas crises econômicas, o que contribui para a não contribuição de pagamentos aos órgãos públicos, o que, segundo economistas, aumenta o déficit econômico do país.

\section{O Jovem e o Mercado de Trabalho}

O mercado de trabalho vem passando por diversas transformações ocasionadas pelas mudanças no cenário econômico, além das novas tecnologias, e isso tem gerado mudanças 
significativas no âmbito trabalhista, exigindo cada vez mais qualificações profissionais e pessoais dos indivíduos. Essas mudanças tem atingido cada vez mais o jovem que busca o seu primeiro emprego, a sua primeira inserção no mundo do trabalho.

Face à exigência de uma maior capacitação, o público jovem tem dificuldade de inserção no mundo do trabalho (SILVA, OLIVEIRA E OLIVEIRA, 2015).

Na visão de Guimarães e Almeida (2013), a dificuldade de inserção do jovem no mercado se dá porque este, muitas vezes abandona os estudos e /ou por causa da sua baixa escolaridade, o que leva a uma má qualidade da aprendizagem.

Os autores supra citados (2013, p. 1) ainda afirmam que “A inserção produtiva dos jovens consolida-se como um grande desafio. Trata-se de um público mais vulnerável, que enfrenta maiores dificuldades de inserção no mercado de trabalho e tende a encontrar ocupações mais precárias $[\ldots] "$.

De acordo com o IBGE - Instituto Brasileiro de Geografia e Estatística IBGE (2015, p. 01), “a inserção dos jovens entre 18 a 24 anos de idade durante o período de 2014 para 2015 teve uma queda percentual de 57,3\% para 53,8\%".

Vê-se que houve uma redução de percentual, e pode-se afirmar que foi devido a uma melhoria na qualificação e dedicação.

Essa redução pode ter se dado tanto pelos desafios enfrentados pelos jovens para conseguir uma vaga no mercado de trabalho, quanto ao maior tempo de dedicação aos estudos (GUIMARÃES: ALMEIDA, 2013).

A Lei 10.097, de 2000, mais conhecida como a lei de aprendizagem, assegura aos jovens a inserção no mercado de trabalho em todas as empresas de médio e grande porte, que são “obrigadas" por esta lei, a contratar um determinado número de aprendizes. Esse número equivale a um percentual de no mínimo 5\% a 15\% do seu quadro. Esta lei foi ampliada pelo Decreto Federal de nº5.598 de 2005. Vale ressaltar que para que haja a inserção desses jovens, os mesmos deverão estar devidamente matriculados e frequentando a escola.

A lei ainda assegura a idade mínima e máximo dos jovens que é de 14 a 24 anos de idade.

\section{Programas/Políticas de Inserção dos Jovens no Mercado de Trabalho}

Muitas foram as políticas que estimulam a inserção dos jovens no mundo do trabalho, visando estimular a renda, a oferta de emprego voltados a fortalecer a empregabilidade no país, as quais passar-se-á a apresentar. 


\section{Plano Nacional de Formação Profissional - Planfor}

Criado em 1995, pela Secretaria de Formação e Desenvolvimento Profissional do Ministério do Trabalho - MT, com a finalidade de desenvolver ações de educação profissional, buscando contribuir para a redução do desemprego e subemprego. Este plano, foi financiado com os recursos do Fundo de Amparo ao Trabalhador - FAT (JORGE, 2018).

O Planfor conseguiu dar maior visibilidade aos jovens, pois estes eram os vistos como mais vulneráveis. No entanto, por causada de inúmeras situações como: carga horária dos cursos ofertados, qualidade dos mesmos, e desarticulação com outras políticas, este plano ficou comprometido (GUIMARÃES; ALMEIDA, 2018).

\section{Programa do Programa Nacional de Primeiro Emprego - PNPE}

Este programa foi cirando em 2003, e foi voltado exclusivamente aos jovens de 16 a 24 anos, provindos de famílias pobres e sem nenhum vínculo empregatícios, também cursando o ensino médio, fundamental ou outros cursos (GUIMARÃES; ALMEIDA, 2018).

Foi a Lei $n^{\circ} 10.748 / 2003$ que criou o PNPE, e alterada pela lei 10.940/2004, regulamentada pelo Decreto $\mathrm{n}^{\circ} 5.199$ de 2004. O seu objetivo estava voltado a "ações de promoção da inserção de jovens no mercado de trabalho e sua escolarização, ao fortalecimento da participação da sociedade no processo de formulação de políticas e ações de geração de trabalho" (BRASIL, 2003).

Em seu artigo $1^{\circ}$, e incisos, a Lei deixa bem claro a sua finalidade, a saber.

\footnotetext{
Art. $1^{\circ} .(\ldots)$

I - a criação de postos de trabalho para jovens ou prepará-los para o mercado de trabalho e ocupações alternativas, geradoras de renda; e

II - a qualificação do jovem para o mercado de trabalho e inclusão social.

Art. 2o O PNPE atenderá jovens com idade de dezesseis a vinte e quatro anos em situação de desemprego involuntário, que atendam cumulativamente aos seguintes requisitos:

I - não tenham tido vínculo empregatício anterior;

II - sejam membros de famílias com renda mensal per capita de até 1/2 (meio) salário mínimo, incluídas nesta média eventuais subvenções econômicas de programas congêneres e similares, nos termos do disposto no art. 11 desta Lei; (Redação dada pela Lei $\mathrm{n}^{\circ} 10.940$, de 2004)

III - estejam matriculados e freqüentando regularmente estabelecimento de ensino fundamental ou médio, ou cursos de educação de jovens e adultos, nos termos dos arts. 37 e 38 da Lei no 9.394, de 20 de dezembro de 1996, ou que tenham concluído o ensino médio; e (Redação dada pela Lei $\mathrm{n}^{\circ} 10.940$, de 2004)

IV - estejam cadastrados nas unidades executoras do Programa, nos termos desta Lei; (Redação dada pela Lei no 10.940 , de 2004)

(...) ( BRASIL, 2003).
} 
Este foi um dos programas voltados a jovem em sua busca pelo primeiro emprego, mas em 2005, mudou-se o foco do mesmo face às dificuldades existentes na época.

\section{Consórcios Sociais da Juventude - CSJS}

Este foi mais um programa que buscou fortalecer a qualificação, sociabilidade e autoestima dos jovens, provenientes de famílias pobres, que estivessem estudando, priorizando dessa vez, os jovens quilombolas, afrodescendentes e indígenas ( GUIMARÃES; ALMEIDA, 2018).

Ainda segundo Guimarães e Almeida (2018), os CSJs buscavam a criação de Centros da Juventude, com a finalidade de promover encontros e ações direcionadas à sociabilidade e à qualificação dos jovens.

\section{Ação Juventude Cristã}

Este programa muito similar aos CSJs, se diferenciava pelo fato de que suas ações eram descentralizadas e voltadas para as regiões com baixo índice de desenvolvimento humano. Vale ressaltar que esse programa era executado por entidades devidamente contratada pelas prefeituras (GUIMARÃES; ALMEIDA, 2018).

\section{Programa Empreendedorismo e Responsabilidade Social}

Programa este direcionado à criação de crédito para os jovens, através de uma linha especial, mas que tinha como requisito primordial uma qualificação através de uma capacitação. Isso dificultou o acesso dos jovens de baixa renda ao programa (GUIMARÃES; ALMEIDA, 2018).

\section{Programa Escola da Fábrica}

Essa um programa que uma a teoria e a prática, buscando, mais uma vez a inserção do jovem no mercado de trabalho. Por sua vez, o programa tinha parceria com empresas e ONGs - Organização Não Governamentais. O acompanhamento pedagógico, bem como a sua 
supervisão e monitoramento, era de responsabilidade o Ministério da Educação (GUIMARÃES; ALMEIDA, 2018).

\section{Programa Nacional de Inclusão de Jovens - Projovem}

Criado em 2005, esse projeto tinha como finalidade ações visando a elevação da escolaridade, e a conclusão do ensino fundamental, estimulando os jovens a terem uma qualificação profissional e a cidadania. As prefeituras eram as responsáveis pela formação. Além do mais, os jovens recebiam a quantia de $\mathrm{R} \$ 100,00$ (cem reais), vinculado à frequência de $75 \%$ (OIT, 2009).

Dois anos depois, em 2007, ocorreu uma mudança no programa, e daí foi criado o Projovem Unificado, onde outros programas já existentes passaram a integrar um só, ou seja, Projovem, Agent Jovem, escola da Fábrica, juventude Cristã e Consócios Sociais da Juventude, que alterou a faixa etária dos jovens, classificando assim: adolescentes jovens de 15 a 17 anos; jovens-jovens de 18 a 24 anos; jovens adultos de 15 a 29 anos.

\section{Programa Nacional de Acesso ao Ensino Técnico e Emprego - Pronatec}

Criado em 2011 pelo Governo Federal, teve como objetivo de ampliar a oferta dos cursos profissionais e tecnológicos de nível médio e de formação inicial.

Como os demais programas, o Pronatec está voltado para os jovens que não têm condições financeiras para ingressar em cursos técnicos. Estes cursos são ofertados pela rede pública federal, Senai e Senac.

\section{Programa Jovem Aprendiz}

Este é um programa do Governo Federal que incentiva as empresas a contratarem os jovens contribuindo assim com a aprendizagem dos mesmos, colaborando assim com o desenvolvimento do país (ANDRADE; JESUS; SANTOS, 2016).

Aprendiz, segundo o Estatuto da Criança e do Adolescente, em seu artigo 62:

Art. 62. Considera-se aprendizagem a formação técnico-profissional ministrada segundo as diretrizes e bases da legislação de educação em vigor (BRASIL1990). 
Já em conformidade com o Decreto Federal no 5.598/2005, em seu art. $2^{\circ}$,

Art. $2^{\circ}$. "Aprendiz é o maior de quatorze anos e menor de vinte e quatro anos que celebra contrato de aprendizagem nos termos do art. 428 da Consolidação das Leis do trabalho - CLT" (BRASIL, 2005).

Todo esse cuidado com o jovem aprendiz está devidamente pautada na Constituição Federal de 1988, com a Emenda de $\mathrm{n}^{\circ} 20$ de 1998, em seu artigo $7^{\circ}$, inciso XXXIII, relacionado ao menor é vedada a proibição de trabalho em algumas situações a saber:

Art. $7^{\circ}(\ldots)$

(..)

XXXIII - proibição de trabalho noturno, perigoso ou insalubre a menores de dezoito e de qualquer trabalho a menores de dezesseis anos, salvo na condição de aprendiz, a partir de quatorze anos.

(...) (BRASIL, 1988)

Dentre os diversos programas que visam a inserção do jovem no mercado de trabalho, há ainda o Programa Jovem Aprendiz, criado pela Lei 10.097 de 2000, posteriormente ampliado pelo Decreto Federal no 5.598 em 2005.

Para Andrade, Santos e Jesus (2016, p. 47),

O Programa Nacional de Aprendizagem é uma iniciativa do governo federal que, a partir de políticas públicas, visa inserir jovens maiores de 14 anos no mercado de trabalho, fazendo com que sejam criadas oportunidades para que estes jovens adentrem, desde cedo, no mercado de trabalho, buscando conciliar trabalho e estudo, conforme exigência das leis trabalhistas.

A Lei 10.097/2000, também é conhecida como a lei da Aprendizagem porque determina que as empresas, seja de médio e/ou grande porte, contratem aprendizes, que passarão a fazer parte de seu quadro de colaboradores. Para tanto, necessário se faz que estes cumpram os requisitos exigidos para tal.

O programa Jovem Aprendiz que é um programa do Governo, cria oportunidades para que os estudantes que estão cursando o ensino médio ou já tenham concluído, possam ter a oportunidade do primeiro emprego e assim, inseridos no mercado de trabalho adquiram mais conhecimento prático e teórico (PROGRAMAS DO GOVERNO, 2018).

A finalidade da Lei 10.097/2000, é promover a inserção de jovens e adolescentes na faixa etária entre 14 e 24 anos no mundo do trabalho, desde que estejam devidamente matriculados e frequentando a escola, ou ainda, que estejam inscritos em programas de aprendizagem ofertados em parceria com o Serviço Nacional de Aprendizagem Industrial SENAI, Serviço Nacional de Aprendizagem Comercial - SENAC, Serviço Nacional de 
Aprendizagem Rural - SENAR, Serviço Nacional de Aprendizagem do Transporte - SENAT (LUZ, 2015).

Para que o contrato de aprendizagem tenha legitimidade deverá existir o registro na Carteira de Trabalho e Previdência Social. O aprendiz deve estar devidamente matriculado e frequentando a escola e inscrito em programa de aprendizagem.

Os jovens inseridos nesse contexto, têm garantidos o recolhimento das obrigações legais sobre os valores de remuneração e gratificações, Fundo de Garantia do Tempo de Serviço (FGTS) recolhimento relativo à contribuição ao Instituto Nacional de Seguridade Social -INSS (LUZ, 2015).

O contrato de trabalho do jovem aprendiz está normatizado no artigo $3^{\circ}$ do Decreto Federal n5.598/2005, que estabelece:

[...] é o contrato de trabalho especial, ajustado por escrito e por prazo determinado não superior a dois anos, em que o empregador se compromete assegurar ao aprendiz, inscrito em programa de aprendizagem, formação técnico-profissional metódica compatível com seu desenvolvimento físico, moral e psicológico, e o aprendiz se compromete a executar com zelo e diligência as tarefas necessárias a essa formação (BRASIL, 2005).

O contrato de trabalho do jovem aprendiz está devidamente regulamentado pela Lei $\mathrm{n}^{\circ}$ 10.097/2000, pelo Decreto $n^{\circ}$ 5.598/2005 e também pela Consolidação das Leis do Trabalho CLT, sem eu artigo 428, pois trata-se de um contrato especial, portanto, deve ser confeccionado obedecendo a todos os pré-requisitos, exigidos para tal, ou seja, escrito e com prazo determinado de no máximo dois anos (ANDRADE; JESUS; SANTOS, 2016).

Vale frisar que a jornada de trabalho do jovem aprendiz não pode ultrapassar de seis horas diárias.

Com relação à extinção do Contrato de trabalho, o artigo 28 do Decreto no 5.598/2005, normatiza que,

\footnotetext{
Art. 28. O contrato de aprendizagem extinguir-se-á no seu termo ou quando o aprendiz completar vinte e quatro anos, exceto na hipótese de aprendiz deficiente, ou, ainda antecipadamente, nas seguintes hipóteses:

I - o desempenho insuficiente ou inadaptação do aprendiz;

II - falta disciplinar grave;

III - ausência injustificada á escola que implique perda do ano letivo; e IV - a pedido do aprendiz (BRASIL, 2005).
}

O programa Jovem Aprendiz consolida todos os demais programas que incluem o jovem na relação escola-trabalho-formação, proporcionando-lhe uma formação técnico-profissional adequada bem como ao desenvolvimento de habilidades e competências. 
As leis estão protegendo o trabalho do jovem, proporcionando-lhe segurança e aprendizagem, bem como experiências profissionais.

\section{Metodologia}

O presente estudo trata-se de uma pesquisa bibliográfica de cunho qualitativo, uma vez que buscou-se informações em obras já publicadas e atualizadas, leis, artigos e sites confiáveis.

Para Gil (2008), a pesquisa bibliográfica dá-se com base em material já elaborado e publicado sobe o tema, devidamente exposto e discutidos no presente estudo.

Ainda sobre pesquisa bibliográfica, Marconi e Lakatos (2017, p. 33) dizem que "é um tipo especifico de produção cientifica, realizada com base em textos, como livros, artigos científicos, dicionários, enciclopédia".

Para chegar ao resultado final, utilizou-se de uma pesquisa qualitativa. Vieira (2009, p. 5-6), comenta que:

Na pesquisa Qualitativa, o pesquisador busca, basicamente, levantar as opiniões, as crenças, o significado das coisas nas palavras dos participantes da pesquisa. Para isso, procura interagir com as pessoas mantendo neutralidade. A pesquisa qualitativa não é generalizável, mas exploratória, no sentido de buscar conhecimento para uma questão sobre a qual as informações disponíveis são, ainda, insuficientes.

O acervo utilizado para contemplar o presente estudo foi devidamente catalogado e escolhido tendo por base as referências mais atualizadas sobre o estudo,

\section{Considerações Finais}

O desenvolvimento do presente estudo possibilitou a análise sobre as políticas/programas públicos existentes para incentivar a inserção do jovem no mercado de trabalho, sem precisar abandonar os estudos, bem como as dificuldades enfrentadas pelos mesmos para conseguir uma vaga nesse mundo tão competitivo, visto que com os constantes avanços tecnológicos se faz necessário ter qualificação profissional para conseguir uma boa colocação no mercado de trabalho.

Pode-se afirmar que com o aumento dos trabalhos informais e as crises econômicas enfrentadas pelo Brasil, a criação dessas politicas/programas públicos foi uma estratégia do 
Governo Federal para inserir indivíduos com idade entre 14 a 24 anos de forma legalizada no mercado de trabalho, assim aumentando a empregabilidade no país.

A Lei de Aprendizagem que é praticamente a unificação dos programas criados anteriormente veio para garantir ao jovem o trabalho formal, onde o mesmo tem todos seus direitos garantidos em lei, como também o possibilita ter uma qualificação profissional sem nenhum prejuízo na sua formação acadêmica.

Através de instituições vinculadas ao programa Jovem Aprendiz os jovens obtêm um conhecimento teórico e prático, sendo o teórico na instituição vinculada e a parte prática nas empresas. Vale ressaltar que a jornada de trabalho não poderá ultrapassar seis horas diárias, possibilitando dessa forma que seja adquirida a experiência profissional.

Dada a importância do assunto, se faz necessária novas pesquisas de como aperfeiçoar as políticas/programas públicos existentes para que cada vez mais os jovens tenham maior acesso ao mercado de trabalho.

Nesse sentido, compreende-se que o programa jovem aprendiz tem como objetivo a inserção do jovem no mercado de trabalho, a fim de conceder uma formação técnicoprofissional, proporcionando experiências dentro das organizações que lhes deixarão mais preparados para o mundo do trabalho, ao mesmo tempo em que garante a conciliação dos estudos com o trabalho, visto que estes podem se tornar cada vez mais capacitados e assim ter maiores oportunidades para conseguir uma boa colocação no mercado de trabalho.

\section{Referências}

ALBORNOZ, S. O que é trabalho. São Paulo: Brasiliense, 2002.

ANDRADE, Júlio Mendonça de; JESUS, Gustavo Santana de; SANTOS, Karlos Kleiton dos. O Programa Jovem Aprendiz e sua importância para os jovens trabalhadores. Disponível em:< https://periodicos.set.edu.br/index.php/direito/article/view/2742> Acesso em 25 Out. 2018.

ARAÚJO, Romilda Ramos; SACHUK, Maria Iolanda. Os Sentidos do Trabalho e suas implicações na formação dos indivíduos inseridos nas organizações contemporâneas. Revista de Gestão USP. São Paulo, v. 14, n. 1, p. 53-66, jan./mar. 2007.

BASTOS, Maurício de Campos. Trabalho Formal e Informal. Disponível em: https://www.trt3.jus.br/escola/download/revista/rev_70_II/Mauricio_Bastos.pdf. Acesso em 20 Set. 2018.

BIBLIA SAGRADA. Genêsis Cap 3. Versículo19. Disponível em:< https://www.bibliaonline.com.br/acf/gn/1> Acesso em 09 Ago. 2018. 
BORGES, Regina Célia Paulineli. Jovem Aprendiz: os sentidos do trabalho expressos na primeira experiência profissional. (Dissertação de Mestrado). Disponível em: <https://repositorio.ufsc.br/handle/123456789/93666> Acesso em 20 Set. 2018.

BRASIL. Constituição da República Federativa do Brasil 1988. Constituição Federal 1988. Disponível em: < http://www.planalto.gov.br/ccivil_03/LEIS/L8069.htm> Acesso em 10 Set. 2018.

Consolidação das Leis do Trabalho - CLT. Decreto-lei $\mathrm{n}^{\circ} 5.452$, de $1^{\circ}$ de maio de 1943, DOU de 09/08/1943. Disponível em:< http://www.trtsp.jus.br/geral/tribunal2/LEGIS/CLT/capa_clt_dinamica.htm> Acesso em 25 Out. 2018.

Decreto Federal no 5.598/2005 de 01 de Dezembro de 2005. Regulamenta a contratação de aprendizes e dá outras providências. Disponível em:< http://www.planalto.gov.br/ccivil_03/_Ato20042006/2005/Decreto/D5598.htm > Aceso em 20 Set. 2018.

Emenda Constitucional $\mathbf{n}^{\mathbf{0}}$ 20, de 15 de Dezembro de 1998. Modifica o sistema de previdência social, estabelece normas de transição e dá outras providências. Disponível em:< http://www.planalto.gov.br/CCIVIL_03/Constituicao/Emendas/Emc/emc20.htm> Acesso em 30 Out. 2018.

. Lei no 8.069, de 13 de julho de 1990. Dispõe sobre o Estatuto da Criança e do Adolescente e dá outras providências. Disponível em:< http://www.planalto.gov.br/ccivil_03/LEIS/L8069.htm> Acesso em 20 Out. 2018.

Lei $\mathbf{n}^{0}$ 10.748, de 22 de outubro de 2003. Cria o Programa Nacional de Estímulo ao Primeiro Emprego para os Jovens - PNPE, acrescenta dispositivo à Lei no 9.608, de 18 de fevereiro de 1998, e dá outras providências. Disponível em:< http://www.guiatrabalhista.com.br/legislacao/l10748.htm> Acesso em 10 Set. 2018.

- Ministério do Trabalho e Emprego. Secretaria de Políticas Públicas de Emprego. PLANFOR: Plano Nacional de Qualificação do Trabalhador. Brasília, 2001.

CARMO, P. S. A ideologia do trabalho. 6. ed. São Paulo: Moderna, 1997

CHIAVENATO, Idalberto. Recursos Humanos. 9.ed. Rio de Janeiro: Elsevier, 2009.

CHIAVENATO, Idalberto. Gestão de Pessoas: o novo papel dos recursos humanos nas organizações. 4 ed. São Paulo: Manole, 2014.

CASTILHO, Marcelo Viana de. A metamorfose do Mercado de Trabalho. Disponível em : < https://www.inesul.edu.br/revista/arquivos/arq-idvol_3_1247259456.pdf> Acesso em 10 Out. 2018.

GIL, Antônio Carlos. Métodos e técnicas de pesquisa social. 5. ed. São Paulo: Atlas, 2008.

GUIA TRABALHISTA. Tipos de trabalho formal e informal, voluntário, autônomo e outros. Disponível em: < https://www.guiatrabalho.com.br/tipos-de-trabalho.html> Acesso em 20 Ago. 2018.

GUIMARÃES, Alexandre Queiroz; ALMEIDA, Mariana Eugenio. Os Jovens e o Mercado de Trabalho: evolução e desafios da Política de Emprego no Brasil. Disponível em: https://periodicos.fclar.unesp.br/temasadm/article/viewFile/6845/4926> Acesso em 30 Ago. 2018.

INSTITUTO BRASILEIRO DE GEOGRAFIA E ESTATÍSTICA. [IBGE] Disponível em:< https://ww2.ibge.gov.br/home/estatistica/economia/perfilmunic/2015/default.shtm Acesso em 28 Set. 2018. 
JORGE, Tiago Antônio da Silva. Plano Nacional de Qualificação do Trabalhador - PLANFOR. Disponível em:< http://www.gestrado.net.br/pdf/316.pdf> Acesso em 30 Set. 2018.

LUZ, Paulo Roberto Morais da. Programa Jovem Aprendiz: um estudo de caso da política pública e suas implicações no mundo to trabalho. https://periodicos.set.edu.br/index.php/direito/issue/archive/viewFile/2742/1628 .> Acesso em 03 Nov. 2018.

MARCONI, Andrade, M. D., LAKATOS, Maria, E. (01/2017). Fundamentos de Metodologia Científica, $\quad 8 \quad$ ed. $\quad$ [Minha Biblioteca]. Disponivel em: https://integrada.minhabiblioteca.com.br/\#/books/9788597010770/>ACesso em 30 Out.2018.

MARTINS, Sergio Pinto. Breve Histórico a respeito do Trabalho. Disponível em:< http://www.revistas.usp.br/rfdusp/article/view/67461> Acesso em 15 Ago. 2018.

ORGANIZAÇÃO INTERNACIONAL DO TRABALHO [OIT]. Trabalho decente e juventude no Brasil. Brasília, 2009.

PROGRAMAS DE GOVERNO. Disponível em:<https://www.infojovem.org.br/oportunidades/ programasde-governo/ > Acesso em 30 Out. 2018.

SCALON, M.C. Ensaios de Estratificação. Belo Horizonte: Argvmentvn, 2009.

SILVA, Annyelle Magda Souza da; OLIVEIRA Mayara Evelin Soares de; OLIVEIRA Rita Patrícia Almeida de; Jovens Administradores e o Mercado de Trabalho. Disponível em:< https:///C:/Users/andre/Desktop/antigo-2015.pdf> Acesso em 25 Set. 2018.

SILVA, Wellington Souza. Mercado de Trabalho. Disponível em: < https://www.infoescola.com/economia/mercado-de-trabalho/. Acesso em 20 Ago. 2018

VIEIRA, Sonia. Como elaborar questionários. Editora Atlas, 2009.

\section{Como citar este artigo (Formato ABNT):}

SILVA, Andreza Bispo da; COSTA, Antonia Valdelucia. Políticas e Programas Públicos que Oportunizam a Inserção do Jovem no Mercado de Trabalho. Id on Line Rev.Mult. Psic., 2019, vol.13, n.43, p. 967-981. ISSN: 1981-1179.

Recebido: 01/12/2018;

Aceito: 03/11/2018 